\title{
Microcysts of the human iris pigment epithelium
}

\author{
ROBERT FISCHER, PAUL HENKIND, AND SAMUEL GARTNER \\ From the Department of Ophthalmology, Montefiore Hospital Medical Center and \\ Albert Einstein College of Medicine
}

SUMMARY Microcysts of the iris pigment epithelium have been described in association with diabetes mellitus, systemic mucopolysaccharidoses, Menkes's syndrome, and in neonates. Our study covers 68 cases obtained at necropsy. We specifically examined the iris pigment epithelium for vacuolation. We found that microcysts are more widespread than previously thought. In our series $57.3 \%$ of the cases reviewed by the light microscope showed microcysts. Of interest was the relationship of malignant neoplasm to iris pigment epithelium microcyst: $69.4 \%$ of cases with malignancy showed microcyst, whereas only $30 \%$ of the cases without neoplasms showed microcysts. Patients treated with exogenous steroid also had a raised incidence of microcysts.

The pigment epithelium of the iris is composed of a double layer of well-differentiated neuroepithelial cells. The cells of the anterior epithelial layer have a muscular basal portion whose elements comprise the dilator muscle, and a pigmented, epithelial apical portion. Those of the posterior layer are varied in size and shape and heavily pigmented. By light microscopy the iris pigment epithelium appears as a dark layer in which intracellular details are hidden by the heavy aggregation of melanin granules. Normally there are no obvious cysts within the iris pigment epithelial cells. However, in a number of conditions alterations of the iris pigment epithelium characterised as vesicles, vacuoles, oedema, or microcysts are found. We prefer the term microcyst(s) for this appearance. This report demonstrates that microcysts of the iris pigment epithelium (MIPE) are more frequent than previously reported, and that they may be associated with a number of disorders including neoplasms and may be induced by corticosteroid administration. We also show that the appearance of microcysts by light microscopy is dependent on the thickness of the histological section.

\section{Materials and methods}

This was a retrospective study of eyes obtained at necropsy during a 3-year period. The eyes were enucleated and fixed in formalin. They were then processed in the usual manner and embedded in paraffin. Sections $9 \mu \mathrm{m}$ thick were cut and stained

Reprint requests to Gartner Library of Ophthalmology, Montefiore Hospital and Medical Center, 111 East 210th Street, Bronx, New York 10467, USA. with haematoxylin and eosin. Eyes with extensive autolytic changes or those with a damaged iris pigment epithelium were excluded. Sixty-eight eyes were found suitable for this study. Particular attention was paid to the appearance of the iris pigment epithelium and it was specifically examined for the presence of microcysts. In several instances in which microcysts were noted the block was recut at $15 \mu \mathrm{m}$ and the thicker section examined.

In all cases the patient's record was reviewed for the pathological diagnosis at the time of death as well as for the medical treatment that had been given during life. The ages of the subjects ranged from 42 to 87 with a mean age of 63 .

\section{Results}

Thirty-nine cases showed definite microcysts and 29 did not (Table 1). Neoplasms of various kinds were the most frequent condition in which microcysts were noted, but they were also found in association with many other disorders. Eight out of 11 patients on high-dosage systemic steroids had evidence of microcysts; 5 of these patients had died of malignant diseases. The microcysts varied from a few cysts in several cells, to many cysts in most or all iris pigment epithelial cells (Figs. 1, 2, 3).

Sections cut at $15 \mu \mathrm{m}$ or greater often failed to show the presence of microcysts that were readily visible at $9 \mu \mathrm{m}$ (Figs. 4, 5).

\section{Discussion}

According to Duke-Elder (1966) Becker made the first reference to vacuolisation of the iris pigment 
Table 1 Results of the present study

\begin{tabular}{|c|c|c|}
\hline Diagnosis & $\begin{array}{l}\text { Number of eyes } \\
\text { MIPE present }\end{array}$ & $\begin{array}{l}\text { Number of eyes } \\
\text { MIPE absent }\end{array}$ \\
\hline Malignancy & 25 & 11 \\
\hline $\begin{array}{l}\text { Adenocarcinoma, G. } \\
\text { Carcinoma, lung } \\
\text { Carcinoma, breast } \\
\text { Adenocarcinoma, pancreas } \\
\text { Adenocarcinoma, prostate } \\
\text { Carcinoma, epidermoid } \\
\text { Papillary carcinoma, bladder } \\
\text { Carcinoma, penis } \\
\text { Adenocarcinoma, gall bladder } \\
\text { Adenocarcinoma, metastatic }\end{array}$ & $\begin{array}{l}8(1) \\
3 \\
3 \\
1 \\
1 \\
1 \\
- \\
- \\
- \\
-\end{array}$ & $\begin{array}{l}- \\
4 \\
1 \\
- \\
- \\
\overline{1} \\
1 \\
1 \\
1\end{array}$ \\
\hline $\begin{array}{l}\text { Melanoma (metastatic) } \\
\text { Krukenberg tumour } \\
\text { Astrocytoma }\end{array}$ & $\begin{array}{l}1 \\
1 \\
-\end{array}$ & 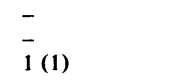 \\
\hline $\begin{array}{l}\text { Hodgkin's disease } \\
\text { Lymphosarcoma } \\
\text { Recticulum cell sarcoma } \\
\text { Acute lymphocytic leukaemia } \\
\text { Histiocytosis }\end{array}$ & $\begin{array}{l}2(1) \\
1(1) \\
1(1) \\
1 \\
1(1)\end{array}$ & $\begin{array}{l}- \\
- \\
\overline{1}\end{array}$ \\
\hline Renal failure & $2(1)$ & 4 \\
\hline $\begin{array}{l}\text { Cerebrovascular accident } \\
\text { Diabetes mellitus }\end{array}$ & $\begin{array}{l}2(1) \\
2\end{array}$ & $\overline{1}$ \\
\hline Neonate with patent ductus & 2 & 1 \\
\hline Pneumonia & 1 & - \\
\hline Arteriosclerotic heart disease & 1 & 2 \\
\hline Systemic lupus erythematosus & 1 & $1(1)$ \\
\hline Cirrhosis & 1 & - \\
\hline Gastrointestinal bleeding & $1(1)$ & $1(1)$ \\
\hline Sepsis & 1 & - \\
\hline Cardiopulmonary arrest & - & 2 \\
\hline Jakob-Creutzfeld disease & - & 1 \\
\hline Bacterial endocarditis & - & 1 \\
\hline Lactic acidosis & - & 1 \\
\hline Cockayne's syndrome & - & 1 \\
\hline Viral hepatitis & - & 1 \\
\hline Multiple myeloma & - & 1 \\
\hline Total & $39(57 \cdot 3 \%)$ & $29(42.6 \%)$ \\
\hline
\end{tabular}

() = Patients treated with steroids. epithelium in diabetes in 1883. Kamocki (1887) later studied the subject in detail. According to Yanoff et al. (1970) this phenomenon is seen in $40 \%$ of enucleated eyes from diabetic patients in which the material within the vacuoles has been identified as glycogen. While diabetes mellitus provides the most frequent and most florid example of MIPE, other conditions show somewhat similar changes. The size of the vacuoles can be diagnostic. In diabetes they often attain a much larger size than in any other condition in which it occurs. The diabetic pigment layer may balloon 2 to 3 times the normal width. In the other conditions they are really microcysts that do not appreciably widen the pigment layer. The systemic mucopolysaccharidoses, particularly MPS I, II, and VI, have similar appearing but smaller microcysts that are filled with membrane bound vacuoles containing mucopolysaccharide (Seelenfreund et al., 1968; Topping et al., 1971 ; Kenyon, 1976). Unlike the changes in diabetes these cystic changes are also seen in the non-pigmented ciliary epithelium and other epithelial tissues in the eye. In 1968 Seelenfreund et al. reported MIPE in a case of Menkes's kinky hair disease, a condition in which serum copper is abnormally low. This finding was later confirmed by Wray et al. (1976). It has also been appreciated by ophthalmic pathologists that some neonatal eyes have MIPE. We noted such cysts in enucleated eyes from patients who were on high-dosage, long-term systemic corticosteroids.

The present study emphasises the fact that MIPE are a common pathological feature associated with many disorders, and in particular with a variety of neoplasms. They are also commonly found in patients who have been on high-dosage corticosteroids. Our study in no way reflects the incidence of the condition, for it was obtained from very selected material. The eyes from cancer patients were generally from those with widely disseminated disease and not from those with limited disease. Furthermore, some of the diagnoses may not be precise, for example, 'renal failure', 'pneumonia',

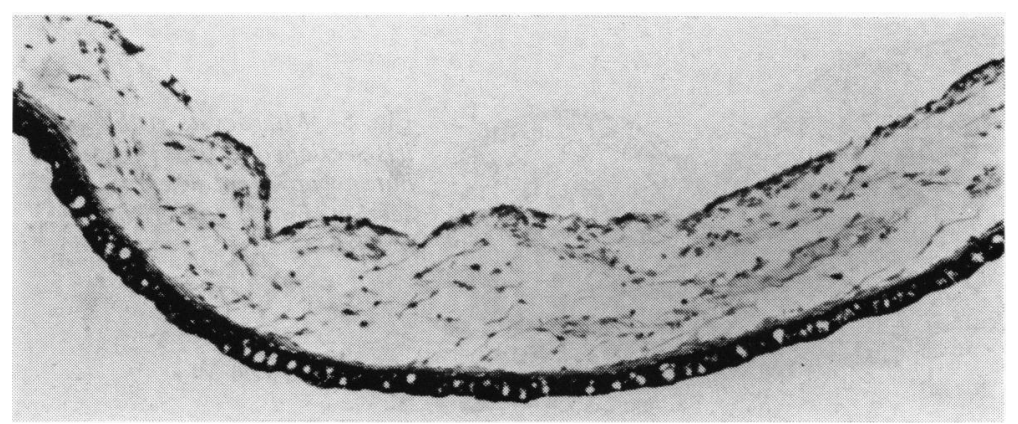

Fig. 1 Microcysts in iris pigment epithelium found in association with alveolar cell carcinoma of lung $(H$ and $E$; $\times 58)$ 
Fig. 2 Microcysts in iris pigment epithelium found in association with prostatic adenocarcinoma $(H$ and $E ; \times 58)$
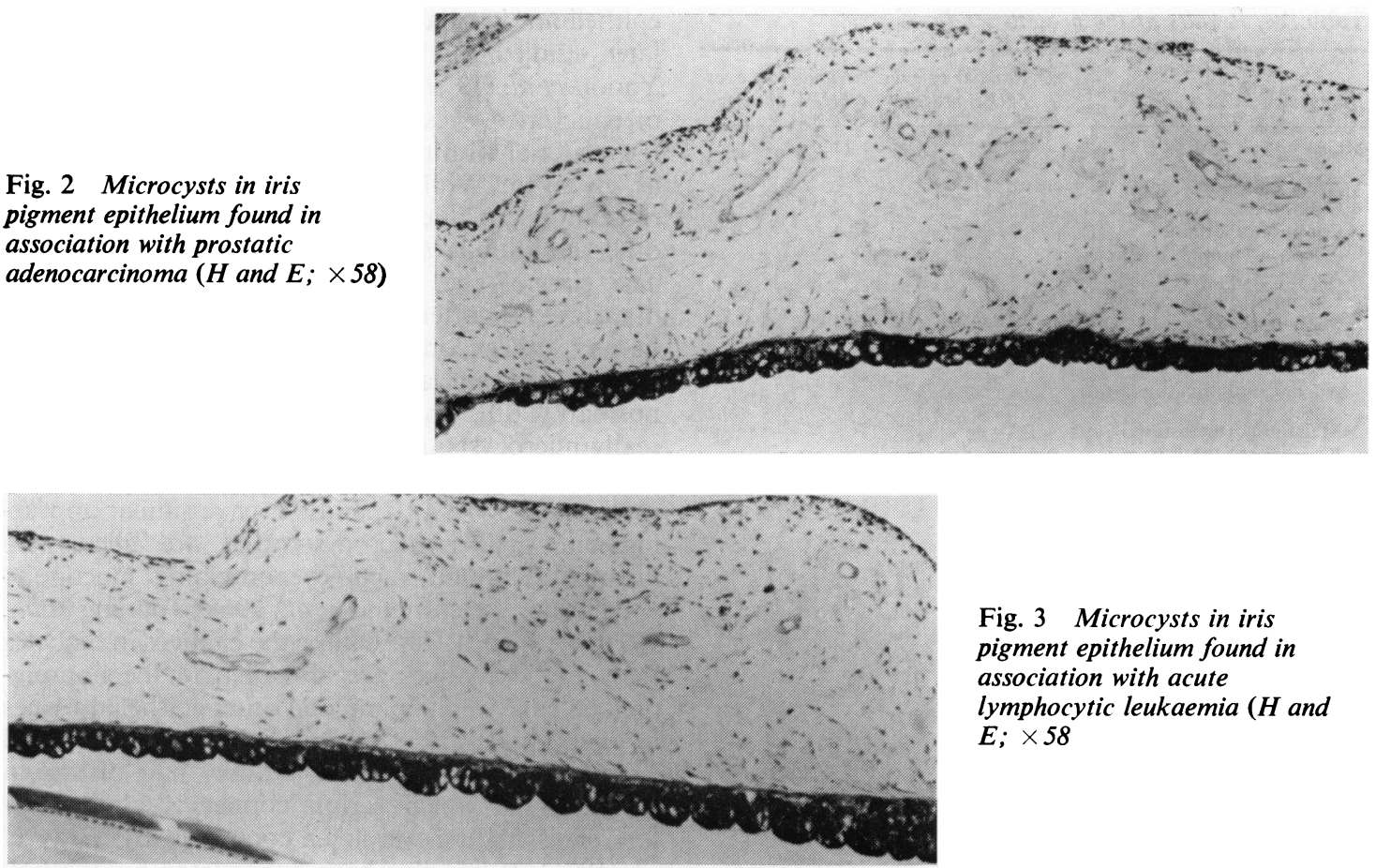

Fig. 3 Microcysts in iris pigment epithelium found in association with acute lymphocytic leukaemia ( $H$ and $E ; \times 58$

Fig. 4 Microcysts visible in iris sectioned at $9 \mu \mathrm{m}$ but not apparent at $15 \mu \mathrm{m}$ (Fig. 5) $(H$ and $E ; \times 58)$
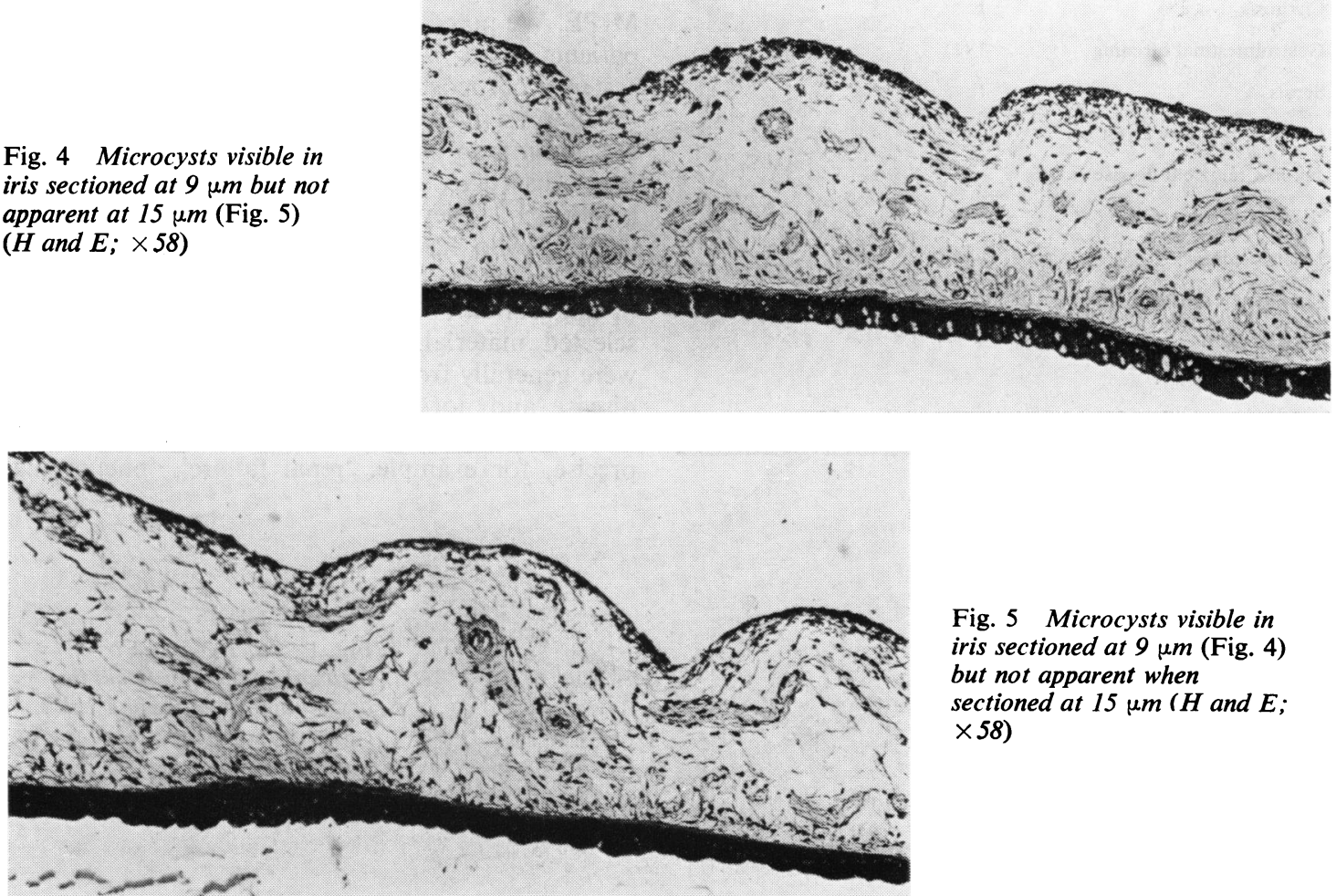

Fig. 5 Microcysts visible in iris sectioned at $9 \mu \mathrm{m}$ (Fig. 4) but not apparent when sectioned at $15 \mu \mathrm{m}(H$ and $E$; $\times 58$ ) 
etc. However, diabetes could be excluded in all cases.

One aspect of this study may explain why we have found such a high incidence of MIPE. Until 2 decades ago and in many laboratories until much more recently most eyes were processed in celloidin. This generally necessitated making relatively thick histological sections, usually $15 \mu \mathrm{m}$ or more thick. We have shown that such thick sections will often mask the presence of any but the larger MIPE. The thinner the sections the more obvious are the microcysts.

We have not identified the material found in the MIPE in the cases described in our present study. Whether such cysts contain glycogen or another storage or breakdown product is not known. One can but speculate that neoplasms significantly alter the body's metabolism and lead to deposits in the iris pigment epithelium and also that exogenous steroids may have a similar role. Biochemical, histochemical, and ultrastructural studies will have to be performed to provide us with the answer.

We find fascinating the fact that so little is known about the function of the iris pigment epithelium. Long considered little more than a curtain to exclude light from the eye, perhaps the iris pigment epithelium will turn out to have multiple functions presently unknown to us.

This study was supported by Grant EY00613 from the National Institute of Health and an unrestricted grant from Research to Prevent Blindness.

\section{References}

Duke-Elder, S. (1966). System of Ophthalmology, Vol. IX, p. 650. Kimpton: London.

Kamocki, V. (1887). Pathologishe-anatomische Untersuchungen von Augen diabetische Individuen. Archiv für Augenheilkunde, 17, 247.

Kenyon, K. R. (1976). Ocular manifestations of SMPS. Birth Defects: Original Article Series, 12, 133-153. March of Dimes.

Seelenfreund, M. H., Gartner, S., and Vinger, P. (1968). The ocular pathology of Menkes' disease. Archives of Ophthalmology, 80, 718-720.

Topping, T. M., Kenyon, K. R., Goldberg, M. F., and Maumenee, A. E. (1971). Ultrastructural ocular pathology of Hunter's syndrome: systemic mucopolysaccharidosis, type II. Archives of Ophthalmology, 86, 164-177.

Wray, S. H., Kuwabara, T., and Sanderson, P. (1976). Menkes' kinky hair disease: a light and electron microscopic study of the eye. Investigative Ophthalmology, 15, $128-138$.

Yanoff, M., Fine, B. S., and Berkow, J. W. (1970). Diabetic lacy vacuolation of iris pigment epithelium: a histological report. American Journal of Ophthalmology, 69, 201-210. 